\title{
Ergocalciferol Versus Cholecalciferol in Non-Dialysis Dependent Chronic Kidney Disease Patients: A Small Retrospective Cohort Study
}

\author{
Akram Al-Makki ${ }^{1}$, Kaitlin Frost ${ }^{2}$, Sang-A Yun ${ }^{2}$, Brian Overholser $^{2}$, Brian Shepler $^{2}$ \\ 1. Indiana University Health Arnett Nephrology, Lafayette IN. ${ }^{2}$ Purdue University College of Pharmacy, West Lafayette, IN.
}

Received, June 4, 2019; Revised, October 11, 2019; Accepted, November 21, 2019; Published, November 30, 2019.

Purpose: The purpose of this retrospective cohort study was to measure the difference between cholecalciferol and ergocalciferol in their ability to effect vitamin $\mathrm{D}$, parathyroid hormone $(\mathrm{PTH})$, calcium, and phosphorous serum concentrations in patients with stage 3 or 4 chronic kidney disease. Methods: This was a retrospective cohort study conducted within a single-center ambulatory nephrology clinic. Patients eligible for the study were identified through medical records displaying each patient's initiation on either ergocalciferol or cholecalciferol from 2013 to 2016. Patients' baseline vitamin D, PTH, calcium, and phosphorous serum concentrations were taken prior to treatment initiation, and patients were reassessed with a second measurement within 12 months of therapy. Results: Out of 149 eligible patients, 110 were excluded. There were 33 patients included on cholecalciferol and 6 patients on ergocalciferol. A significant difference was observed in the percent change of phosphorous serum concentrations from baseline following drug administration $(\mathrm{p}=0.03)$. The mean changes from baseline to final serum phosphorous concentrations $(\mathrm{mg} / \mathrm{dL})$ were 0.12 and -0.3 for cholecalciferol and ergocalciferol, respectively. There was no significant difference in vitamin D (14.9, 15.1, p=0.97), PTH (5.6, 2.3, $\mathrm{p}=0.72)$, or calcium $(0.05,-0.17, \mathrm{p}=0.08)$ serum concentrations between cholecalciferol and ergocalciferol, respectively. There was a statistically significant increase in the mean change in serum phosphorous concentrations within the cholecalciferol group compared to the ergocalciferol group. Conclusion: In this small pilot study, cholecalciferol treatment appeared to increase serum phosphorous concentrations compared to ergocalciferol. These observations may warrant further large-scale studies that are appropriately powered to validate such findings.

\section{INTRODUCTION}

25-hydroxyvitamin D $(25[\mathrm{OH}] \mathrm{D})$ deficiency $(<19$ $\mathrm{ng} / \mathrm{mL})$ and insufficiency $(20-30 \mathrm{ng} / \mathrm{mL})$ are common complications in patients with stage 3 and 4 chronic kidney disease (CKD) that tend to cause poor outcomes.. ${ }^{1,2}$ Low vitamin D concentrations arise from both inadequate dermal synthesis and reduced intake of vitamin $\mathrm{D}$. The reduction in vitamin D concentrations predisposes patients to the possibility of developing secondary hyperparathyroidism. ${ }^{2}$ Low concentrations of vitamin $\mathrm{D}$ result in poor calcium absorption which causes the parathyroid gland to begin to release parathyroid hormone (PTH) in order to induce bone resorption, thereby releasing more calcium into the blood stream to account for the hypocalcemia. Cholecalciferol, an animal-based sterol, and ergocalciferol, a plant-based sterol, are the inactive forms of vitamin D used to supplement patients who are deficient or insufficient. ${ }^{3}$ The optimal method of $25(\mathrm{OH}) \mathrm{D}$ repletion is currently unknown, and trials analyzing the comparative efficacy of cholecalciferol and ergocalciferol in this population are lacking. ${ }^{3}$ Vitamin D supplementation can be used to slow the progression of secondary hyperparathyroidism, as well as maintain calcium and phosphate homeostasis. ${ }^{4}$ There are many studies that have shown a greater potency with the use of cholecalciferol; $;^{5-8}$ however, other studies have shown that ergocalciferol is equally as effective as cholecalciferol. ${ }^{9-10}$ In order to determine the vitamin D supplementation efficacy of either agent, $25(\mathrm{OH})$ $\mathrm{D}$ serum concentrations are commonly used as a biomarker. The recommendations from the Kidney Disease: Improving Global Outcomes Organization (KDIGO) do not specify which of these agents is more effective for $25(\mathrm{OH}) \mathrm{D}$ repletion. ${ }^{11}$

Prior to February 2016 our center checked the $25(\mathrm{OH}) \mathrm{D}$ concentrations routinely in patients with

Corresponding Author: Brian Shepler, PharmD., Assistant Dean for Engagement and Partnerships Clinical Associate Professor of Pharmacy Practice, Purdue University College of Pharmacy, 575 Stadium Mall Drive, West Lafayette, IN USA 47907, E-mail: sheplerb@purdue.edu 
stage 3 and 4 chronic kidney disease after initial consultation with a nephrologist. The patients that were found to have low vitamin D serum concentrations $(<30 \mathrm{ng} / \mathrm{mL})$ were treated according to the ergocalciferol protocol in Table 1.

In February of 2016, the center changed all patients from ergocalciferol to cholecalciferol. This change was based on a literature review and adherence feedback received from patients who reported that a once daily dosing regimen with cholecalciferol was easier to adhere to when compared to weekly and monthly dosing regimens with ergocalciferol. Two reports from the literature demonstrated that cholecalciferol had a higher potency and efficacy in humans compared to ergocalciferol. ${ }^{5,8}$ This information strongly influenced the decision to change patients from ergocalciferol to cholecalciferol. The new protocol is displayed in Table 2.

Outcome data was needed to determine if the patients were benefiting from this change from ergocalciferol to cholecalciferol. The retrospective study described herein examines the outcomes for the primary endpoint, being the variation on serum concentrations for vitamin $\mathrm{D}$, parathyroid hormone $(\mathrm{PTH})$, calcium, and phosphorous in patients taking cholecalciferol compared to ergocalciferol in an ambulatory nephrology clinic in the Midwest. The primary objective of this work was to determine if the commercially available vitamins D products (cholecalciferol and ergocalciferol) have different effects on vitamin $\mathrm{D}$, phosphorous, $\mathrm{PTH}$, and calcium serum concentrations.

\section{METHODS}

An approval to do the study was granted from the Institutional Review Board (IRB). One of the primary investigators was then granted limited review only access to Epic Electronic Health Records (Epic Systems Corp.) from March 1, 2017 until April 26, 2017. Between this time period, the primary investigator used this access to conduct retrospective chart reviews on a password secured computer. The primary investigator extracted patients' information from the medical database from January 2013 to May 2017. None of the patients' identifying information used in the retrospective research was permitted to leave the clinic, ensuring compliance with Health Insurance Portability and Accountability Act (HIPAA) policies.

Table 1. Ergocalciferol Dosing Protocol

\begin{tabular}{|c|c|c|c|c|c|}
\hline $\begin{array}{l}\text { Serum } \\
25(\mathrm{OH}) \mathrm{D} \\
(\mathrm{ng} / \mathrm{mL})\end{array}$ & Definition & & $\begin{array}{l}\text { Ergocalciferol Dose (Vitamin } \\
D_{2} \text { ) }\end{array}$ & Duration (months) & Comment \\
\hline$<10$ & $\begin{array}{l}\text { Severe Vitamin } \\
\text { Deficiency }\end{array}$ & $\mathrm{D}$ & $\begin{array}{l}50,000 \text { IU/wk x } 12 \text { weeks } \\
\text { orally; then monthly }\end{array}$ & 6 months & $\begin{array}{l}\text { Measure } 25(\mathrm{OH}) \mathrm{D} \\
\text { levels after } 6 \text { months }\end{array}$ \\
\hline 10-19 & $\begin{array}{l}\text { Mild Vitamin } \\
\text { Deficiency }\end{array}$ & $\mathrm{D}$ & $\begin{array}{l}50,000 \mathrm{IU} / \mathrm{wk} \times 4 \text { weeks orally } \\
\text { then } 50,000 \mathrm{IU} / \text { month orally }\end{array}$ & 6 months & $\begin{array}{l}\text { Measure } 25(\mathrm{OH}) \mathrm{D} \\
\text { levels after } 6 \text { months }\end{array}$ \\
\hline 20-30 & $\begin{array}{l}\text { Vitamin } \\
\text { Insufficiency }\end{array}$ & D & $50,000 \mathrm{IU} / \mathrm{month}$ orally & 6 months & \\
\hline
\end{tabular}

Table 2. Cholecalciferol Dosing Protocol

\begin{tabular}{|c|c|c|c|c|}
\hline $\begin{array}{l}\text { Serum } \\
25(\mathrm{OH}) D \\
(\mathrm{ng} / \mathrm{mL})\end{array}$ & Definition & $\begin{array}{l}\text { Cholecalciferol } \\
\text { (Vitamin } D_{3} \text { ) }\end{array}$ & Duration (months) & Comments \\
\hline$<10$ & $\begin{array}{l}\text { Severe Vitamin } \\
\text { Deficiency }\end{array}$ & $\begin{array}{l}5,000 \mathrm{IU} / \text { day } \times 12 \text { weeks } \\
\text { orally; then reduce to } 2,000 \\
\text { IU/day x } 3 \text { months orally }\end{array}$ & 6 months & $\begin{array}{l}\text { Measure } 25(\mathrm{OH}) \mathrm{D} \\
\text { levels after } 6 \text { months }\end{array}$ \\
\hline 10-19 & $\begin{array}{l}\text { Mild Vitamin } \\
\text { Deficiency }\end{array}$ & $\begin{array}{l}5,000 \mathrm{IU} / \text { day } \times 4 \text { weeks } \\
\text { orally; then } 2,000 \mathrm{IU} / \text { day } \\
\text { orally } \times 5 \text { months }\end{array}$ & 6 months & $\begin{array}{l}\text { Measure } 25(\mathrm{OH}) \mathrm{D} \\
\text { after } 6 \text { months }\end{array}$ \\
\hline 20-30 & Vitamin D Insufficiency & $\begin{array}{l}2,000 \mathrm{IU} / \text { day x } 6 \text { months } \\
\text { orally }\end{array}$ & 6 months & \\
\hline
\end{tabular}


This study was a single-centered retrospective cohort study conducted to assess the effects of ergocalciferol versus cholecalciferol on the serum concentrations of vitamin $\mathrm{D}, \mathrm{PTH}$, calcium, and phosphorous in patients with stage 3 or 4 chronic kidney disease. Out of 149 patients eligible for the study, 39 were included. These patients met the following criteria: 18-65 years old, treatment initiation with either ergocalciferol or cholecalciferol from 2013 to 2016, and a diagnosis of either stage 3 or 4 chronic kidney disease. Patients were excluded from the trial if they had been switched from ergocalciferol to cholecalciferol or vice versa, if they had discontinued treatment during the time span from 2013 to 2016, if they were on dialysis, or if their laboratory values could not be obtained for analysis. The primary endpoint of the investigation was to evaluate the changes in serum concentration of vitamin D, PTH, calcium, and phosphorous between ergocalciferol and cholecalciferol.

\section{STATISTICAL ANALYSIS}

The change from baseline of vitamin D, PTH, calcium, and phosphorous were calculated following cholecalciferol or ergocalciferol administration. The normality of the data was assessed using the Kolmogorov-Smirnov test. The statistical analysis was performed using the two-tailed Student's t-test or the Mann Whitney test for continuous variables that did not follow a Gaussian distribution. Alpha was set to 0.05 . All statistical analyses were performed with SPSS software (release 24, SPSS Inc., Chicago, IL).

\section{Procedure:}

The initial serum concentrations of all four biomarkers were taken prior to the initiation of treatment to serve as a baseline measurement. A second serum concentration measurement was then taken within 6-12 months after initiation of treatment. These values were then recorded into an excel spread sheet and were evaluated for statistical differences as outlined above.

\section{RESULTS}

Out of the 39 included patients within this observational study, 33 patients were treated with cholecalciferol and 6 patients were treated with ergocalciferol. The baseline characteristics of the included patients are presented in Table 3. The preliminary analysis showed that there was not a statistically significant difference in the percent change of vitamin D serum concentrations (14.9, 15.1, $\mathrm{p}=0.97)$, PTH serum concentrations $(5.6,2.3$, $\mathrm{p}=0.72)$, or calcium serum concentrations $(0.05$, $0.17, \mathrm{p}=0.08$ ) from baseline following drug administration between cholecalciferol and ergocalciferol, respectively. In contrast, there was a statistically significant difference in the percent change of phosphorous serum concentrations $(0.12$, $-0.3, \quad \mathrm{p}=0.03$ ) from baseline following drug administration between cholecalciferol and ergocalciferol, respectively (Figure 1). The mean baseline and final percent change measures are presented in Table 4.

Table 3. Baseline Characteristics

\begin{tabular}{|c|c|c|c|c|}
\hline & & Cholecalciferol $(n=33)$ & $\begin{array}{l}\text { Ergocalciferol } \\
(n=6)\end{array}$ & P-value \\
\hline Age, mean (SD) & & $52.9(8.41)$ & $53.3(1.97)$ & 0.72 \\
\hline Weight, mean (SD) & & $225.24(50.1)$ & $209.3(45.5)$ & 0.48 \\
\hline Body-mass index, mean (SD) & & $34.3(6.95)$ & $33.3(5.43)$ & 0.98 \\
\hline \multirow[t]{3}{*}{ Sex, number $(\%)$} & & & & 0.41 \\
\hline & Male & $18(54.5 \%)$ & $2(33.3 \%)$ & \\
\hline & Female & $15(45.5 \%)$ & $4(66.7 \%)$ & \\
\hline \multirow[t]{3}{*}{ Race, number (\%) } & & & & 0.99 \\
\hline & Hispanic & $3(9.1 \%)$ & $0(0 \%)$ & \\
\hline & Non-Hispanic & $30(90.9 \%)$ & $6(100 \%)$ & \\
\hline \multicolumn{5}{|c|}{ Coexisting conditions, number $(\%)$} \\
\hline & Diabetes & $12(36.4 \%)$ & $4(66.7 \%)$ & 0.21 \\
\hline & Hypertension & $19(57.6 \%)$ & $4(66.7 \%)$ & 0.99 \\
\hline
\end{tabular}




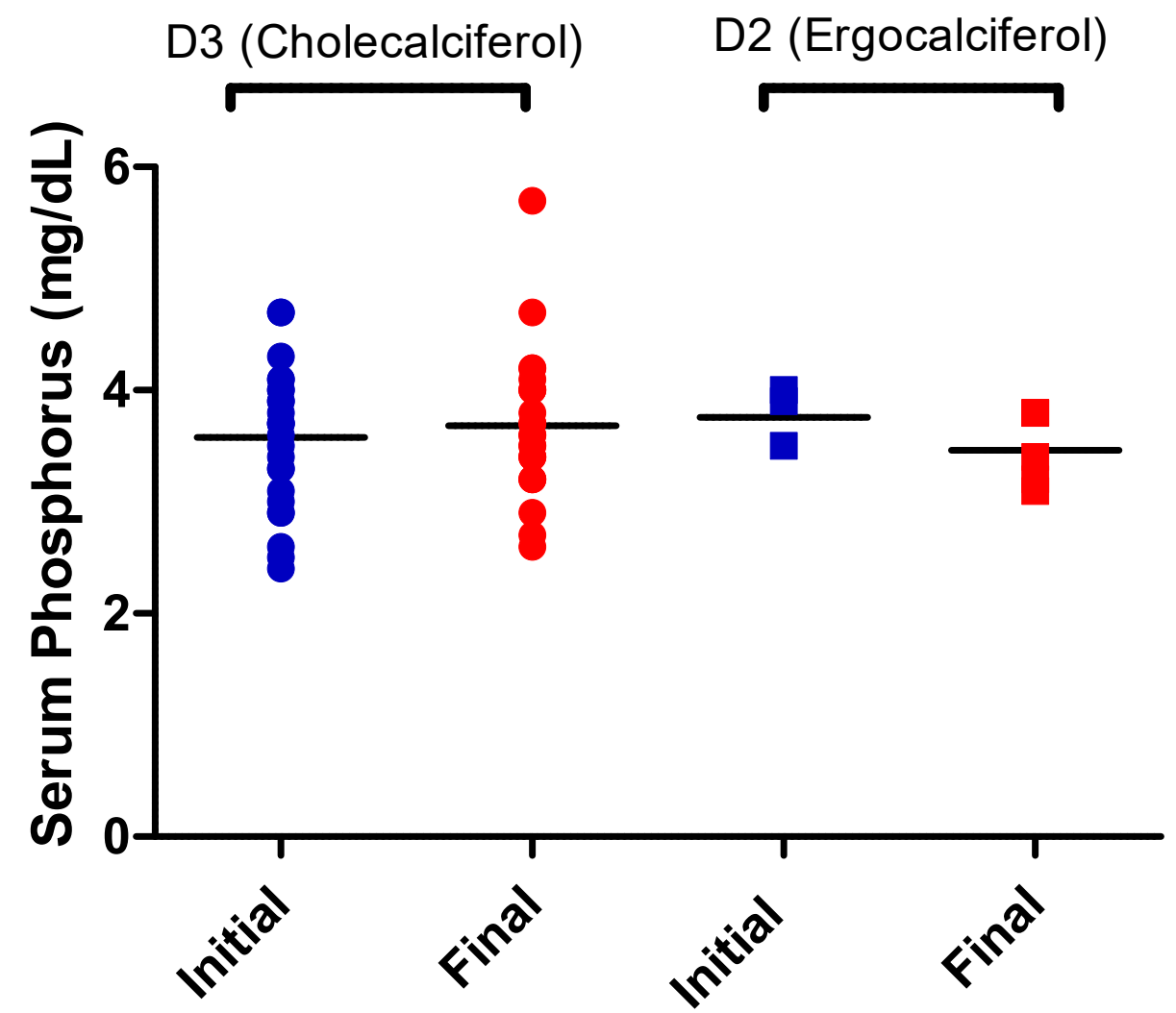

Figure 1. Phosphorus serum concentration changes from baseline to study end between ergocalciferol and cholecalciferol.

Table 4. Primary End Point Values

\begin{tabular}{llll}
\hline Outcome & Cholecalciferol $(\mathbf{n}=\mathbf{3 3})$ & Ergocalciferol $(\mathbf{n}=\mathbf{6})$ & P-value \\
\hline Phosphorous difference, mean (SD) & $0.12(0.40)$ & $-0.3(0.29)$ & 0.03 \\
Vitamin D difference, mean (SD) & $14.9(12.2)$ & $15.1(9.1)$ & 0.97 \\
PTH difference, mean (SD) & $5.6(35.3)$ & $2.3(5.5)$ & 0.72 \\
Calcium difference, mean (SD) & $0.05(0.38)$ & $-0.17(0.22)$ & 0.08 \\
\hline
\end{tabular}

\section{DISCUSSION}

Higher 25(OH) D serum concentrations are thought to have a positive impact on bone health because of the endocrine actions of its active metabolite, 1, $25(\mathrm{OH}) 2 \mathrm{D}$, on the intestines, parathyroid glands, and the bones. In addition, there is evidence that $25(\mathrm{OH}) \mathrm{D}$ may play a role in regulating both calcium and PTH metabolism separate from the hormonal effects of kidney-synthesized 1, 25(OH)2D. ${ }^{1} \quad$ At this study site, prior to February of 2016, the $25(\mathrm{OH})$ D serum concentrations were checked routinely in patients with stages 3 and 4 CKD after initial consultation with the nephrologist as recommended by KDIGO. ${ }^{12}$ The patients who were found to have low vitamin D (below $30 \mathrm{ng} / \mathrm{ml}$ ) were treated with ergocalciferol according to a simplified dosing protocol. ${ }^{13}$ In February of 2016, the nephrologists changed all patients from ergocalciferol to cholecalciferol based on a review of the literature and direct feedback from patients who reported that it is easier to remember to take a daily dose than a weekly or monthly dose. ${ }^{5,8}$ The patients who were found to have low vitamin D (below $30 \mathrm{ng} / \mathrm{ml}$ ) were treated according to a simplified dosing protocol using cholecalciferol. A possible limitation to this study was that slight dosing modifications were made to the protocols in the referenced studies above by the nephrologists and this variation in dosing and adherence could have affected the results.

Cholecalciferol caused an increase in serum phosphorous concentrations when compared to 
ergocalciferol in this study, suggesting that cholecalciferol may increase the amount of phosphorous absorption within the intestinal lining; however, there is no reported evidence in the literature of how this may happen mechanistically. Another randomized placebo controlled trial of 100 subjects also reported an increase in serum phosphorus concentration after cholecalciferol administration but did not comment on possible mechanisms. ${ }^{14}$ Hyperphosphatemia is independently associated with a high mortality risk in the chronic kidney disease population, and serum phosphate levels $>3.5 \mathrm{mg} / \mathrm{dl}$ are associated with an increased risk of death. ${ }^{15}$ Therefore further investigation may be warranted to determine the effect of cholecalciferol compared to ergocalciferol in terms of mortality.

There were some other limitations to this study. The work was all conducted at a single center which reduced the generalizability of the observations. The majority of the patients within this study were nonHispanic which limited the external validity of the results due to the unequal representation of population groups. The high rate of patient exclusion and small sample size for this study also reduced the generalizability and the external validity of the study; however, even with the high rate of patient exclusion, the sample size was large enough to demonstrate a statistically significant difference between the two vitamin $\mathrm{D}$ treatments. In addition, the amount of time patients had been receiving vitamin D supplementation was not collected nor was the dietary habits and co-administration of phosphate binders recorded. Other potential confounding factors were controlled as much as possible. For example, including only stage 3-4 patients to avoid the effects of vitamin D analogs often seen in stage 5 , excluding patients who were switched from one vitamin $\mathrm{D}$ to another as there would have been no washout period, and excluding patients who stopped and started therapy were all employed. These exclusions helped control the analysis but also limited the final subject pool. Finally of note, this was not a hypothesis driven study but rather an exploratory study and we did not expect to see differences in laboratory values.

\section{CONCLUSION}

In this small retrospective pilot study, cholecalciferol treatment was observed to increase serum phosphorous concentrations when compared to ergocalciferol. In other studies, high serum phosphorous concentrations have been linked to higher mortality. Therefore, additional studies may be helpful in evaluating this association and the effects of cholecalciferol versus ergocalciferol in terms of mortality.

\section{REFERENCES}

1. Melamed M, Chonchol M, Gutierrez C, KalantarZadeh K, Kendrick J, Norris K, et al. The Role of Vitamin D in CKD Stages 3 to 4: Report of a Scientific Workshop Sponsored by the National Kidney Foundation. Am J Kidney Dis. 2018;72(6):834-45.

2. Coburn J, Maung H. Use of active vitamin D sterols in patients with chronic kidney disease, stages 3 and 4. Kidney Int Suppl. 2003;63(85):S49-S53.

3. Wetmore J, Kimber C, Mahnken J, Stubbs J. Cholecalciferol v. ergocalciferol for 25hydroxyvitamin $\mathrm{D}(25(\mathrm{OH}) \mathrm{D})$ repletion in chronic kidney disease: a randomised clinical trial. Br J Nutr. 2016;116(12):2074-2081.

4. Williams S, Malatesta K, Norris K. Vitamin D and chronic kidney disease. Ethn Dis 2009;19:8-11.

5. Heaney R, Recker R, Grote J, Horst R, Armas L. Vitamin D3 is more potent than vitamin D2 in humans. J Clin Endocrinol Metab. 2001;96:E447E452.

6. Mangoo-Karim R, Da Silva Abreu J, Yanev G, Perez N, Stubbs J, Wetmore J. Ergocalciferol versus Cholecalciferol for Nutritional Vitamin D Replacement in CKD. Nephron. 2015;130:99-104.

7. Alam U, Chan A, Buazon A, Van Zeller C, Berry J, Jugdey R, et al. Differential effects of different vitamin $\mathrm{D}$ replacement strategies in patients with diabetes. J Diabetes Complications. 2014;28(1):6670.

8. Binkley N, Gemar D, Engelke J, Gangnon R, Ramamurthy R, Krueger D, et al. Evaluation of ergocalciferol or cholecalciferol dosing, $1600 \mathrm{IU}$ daily or 50,000 IU monthly in older adults. J Clin Endocrinol Metab. 2011;96:981-988.

9. Holick M, Biancuzzo R, Chen T, Klein E, Young A, Bibuld D, et al. Vitamin D2 is as effective as vitamin D3 in maintaining circulating concentrations of 25hydroxyvitamin D. J Clin Endocrinol Metab. 2008;93:677-681.

10. Gordon C, Williams A, Feldman H, May J, Sinclair L, Vasquez A, et al. Treatment of hypovitaminosis D in infants and toddlers. J Clin Endocrinol Metab. 2008;93:2716-21.

11. Kidney Disease: Improving Global Outcomes (KDIGO) CKD-MBD Work Group. KDIGO clinical practice guideline for the diagnosis, evaluation, prevention, and treatment of Chronic Kidney Disease-Mineral and Bone Disorder (CKD-MBD). Kidney Int Suppl. 2009;76(113):S1-S130. 
12. Kidney Disease: Improving Global Outcomes (KDIGO) CKD-MBD Work Group. KDIGO clinical practice guideline for the diagnosis, evaluation, prevention, and treatment of Chronic Kidney Disease-Mineral and Bone Disorder (CKD-MBD). Kidney Int Suppl. 2009;76(113):S22-S49.

13. Griend V, McQueen R, Linnebur S, and Vondracek S. Prescription ergocalciferol dosing for vitamin D repletion: a retrospective evaluation. Pharmacotherapy. 2012;32(2):135-41.
14. Al-Bayyari N, Al-Zeidaneen S, Hailat R, and Hamadneh $\mathrm{J}$ et al. Vitamin D3 prevents cardiovascular diseases by lowering serum total homocysteine concentrations in overweight reproductive women: A randomized, placebocontrolled clinical trial. Nutr Res. 2018;59:65-71.

15. Kestenbaum B, Sampson J, Rudser K, Patterson D, Seliger S, Young B, et al. Serum phosphate levels and mortality risk among people with chronic kidney disease. J Am Soc Nephrol. 2005;16:520-528. 